\title{
Yves Poncelet, Pierre l'Ermite (1863-1959). Prêtre, journaliste à La Croix et romancier. Présence catholique à la culture de masse
}

Paris, Éditions du Cerf, 2011, 663 p.

Frédéric Gugelot

\section{(2) OpenEdition \\ Journals}

Édition électronique

URL : http://journals.openedition.org/assr/22945

DOI : 10.4000 /assr.22945

ISSN : $1777-5825$

Éditeur

Éditions de l'EHESS

Édition imprimée

Date de publication : 31 décembre 2011

Pagination : 261

ISBN : 9782713223273

ISSN : 0335-5985

\section{Référence électronique}

Frédéric Gugelot, «Yves Poncelet, Pierre l'Ermite (1863-1959). Prêtre, journaliste à La Croix et romancier. Présence catholique à la culture de masse », Archives de sciences sociales des religions [En ligne], 156 | octobre-décembre 2011, document 156-94, mis en ligne le 16 février 2012, consulté le 21 septembre 2020. URL : http://journals.openedition.org/assr/22945 ; DOI : https://doi.org/10.4000/ assr.22945

Ce document a été généré automatiquement le 21 septembre 2020.

(C) Archives de sciences sociales des religions 
Yves Poncelet, Pierre l'Ermite (1863-1959). Prêtre, journaliste à La Croix et romancier. Présence catholique à la culture de masse

Paris, Éditions du Cerf, 2011, 663 p.

Frédéric Gugelot

\section{RÉFÉRENCE}

Yves Poncelet, Pierre l'Ermite (1863-1959). Prêtre, journaliste à La Croix et romancier.

Présence catholique à la culture de masse, Paris, Éditions du Cerf, 2011, 663 p.

1 Cette thèse, soutenue en 2004, parait enfin. Elle offre une approche historique d'un des auteurs les plus féconds du catholicisme littéraire $d u x^{e}$ siècle, Pierre l'Ermite, pseudonyme de l'abbé Edmond Loutil. Publié dans La Croix de 1891 à 1959, il rédige trois mille chroniques et vingt-neuf livres. En soixante-dix ans de carrière, il a été lu par quatre générations de catholiques. Ses tirages sont très importants et pourtant ses livres sont considérés largement comme une sous-littérature, destinée à un souspublic, d'enfants, de femmes ou de prêtres. Paru en 1899, La Grande Amie atteint 370000 exemplaires en 1930 alors que La Vieille Fille (1921) atteint 220000 exemplaires en 1927. Le grand succès reste Comment j'ai tué mon enfant, paru en 1921, qui atteint 358000 exemplaires en 1959. Edmond Loutil participe donc de ce véritable " torrent de papier " (Loïc Artiaga, Presses universitaires de Limoges, 2007) qu'est le catholicisme du tournant du siècle où presse, essais, fictions, théâtre proposent une contre-culture à la République laïque. Face à la mutation de la modernité, le catholicisme oscille entre deux types de comportements. Le premier se définit à contre-courant par l'affirmation résolue et nette d'une identité et d'une visibilité catholique. Il s'exprime dans l'élaboration d'une contre-société (écoles et collèges catholiques, scoutisme, action 
catholique et autres éléments de la subculture catholique...). Le second parie sur l'insertion dans les réalités sociales et culturelles de son temps. Pierre l'Ermite appartient au premier courant, il disparait quand le second s'affirme au sortir de la Seconde Guerre mondiale. Il est une des formes de la contre-offensive catholique, véritable « contre-réforme » du monde moderne, véritable "réforme » catholique, qui donne à l'Église les armes pour lutter contre la sécularisation et la laïcisation des sociétés européennes. Pierre l'Ermite apparaît alors comme un magnifique exemple de cet engagement dans les moyens de la modernité pour combattre celle-ci. Pourtant le choix de la fiction n'est pas évident au sein du catholicisme, et le roman reste longtemps objet de méfiance. C'est que pour faire face à la massification de la culture "Lorsque dans le courant du siècle dernier, le roman cessa d'être "une liqueur fine distillée à l'usage des palais raffinés" pour devenir populaire (...) et pour porter à tous des idées et des thèses" -, l'abbé Bethléem (Romans à lire, romans à proscrire, Paris, Édition de la Revue des Lectures, 1928, p. 449) énonce un double devoir, la création d'une censure (ce fut son œuvre) et celle d'une littérature catholique. Les censeurs catholiques croient donc à l'influence de la littérature sur l'esprit et la vie du lecteur, influence qui peut devenir néfaste à la foi et aux mœurs. Pierre L'Ermite offre cette fiction aux traits catholiques et justifie ainsi son choix : "C'est ainsi que j'ai été amené à faire des romans... parce que c'est surtout cela qu'on lit, et qu'ils peuvent et doivent servir de véhicule à l'idée française et chrétienne » (la Croisade de la presse, 71, 5 nov. 1903, p. 377. Cité par Y. Poncelet).

2 Y. Poncelet croise avec bonheur la vie du clerc et l'élaboration de son œuvre. L'ouvrage s'articule selon un plan chronologique qui permet de suivre l'entrée dans la carrière de romancier d'un prêtre de banlieue qui aspire à renouveler l'apologétique. Il débute dans la presse car « la parole du prêtre dans son église n'atteint guère que les convertis. Le journal, lui, va partout» (p.59). Pour Edmond Loutil, la presse est une arme de combat. Ses romans, comme ses articles, offrent aux lecteurs conseils, assurances, valorisation de soi mais aussi distractions et défoulements. Ils véhiculent une vision tragique de l'existence, où sacrifices et morts ne manquent pas et où les récompenses ici-bas sont rares. Ardent polémiste, Edmond Loutil rejette la marginalisation du catholicisme. Ses ennemis sont le laïcisme, les loges franc-maçonnes, le socialisme et ses avatars. D'un patriotisme absolu, il ne sépare jamais la France et le catholicisme et donne à l'Église un rôle normatif : « sans religion, la civilisation n'est qu'une façade (...) et la bête humaine est toujours là, prête à se réveiller en ses pires instincts » (p. 566). Les thèmes sont variés mais une constante se dessine : les romans de la famille (amour, mariage, relations dans le couple, relations parents-enfants...) et la question de la vocation et de son sens. Par exemple, Mieux que le mariage loue la grandeur du sacerdoce et suscite un imaginaire apte à rendre désirable un engagement socialement lourd: "Qui dira le rayonnement d'une âme de prêtre !... Il passe toutes ses journées à faire le bien... à défendre les vérités, sans lesquelles le désespoir serait dans tous les cœurs. Il baptise, il confesse, il apprend le catéchisme, il visite les malades, il aide les désespérés à continuer l'existence... Il célèbre la messe... Il ne fonde pas de famille, mais il est de la famille de tout le monde. Le prêtre est le centre de la vie spirituelle d'un pays " (Paris, Maison de la Bonne Presse, 1946, 190, p. 31-32). Son écriture n'appartient jamais aux grands courants esthétiques mais son style imagée, où abondent dialogue et ponctuation, participe de son succès. Ces effets rendent vivants des situations exemplaires, des cas de conscience qui donnaient à ses lecteurs le sentiment d'y trouver des réponses à leurs propres interrogations. Les impératifs de la thèse pèsent 
néanmoins : bien que Pierre l'Ermite se présente comme un observateur pertinent de la société observé depuis le confessionnal et le prebytère, ses textes servent une cause. Mais l'usure sur un gros demi-siècle est réelle; après-guerre, il ne parvient plus à renouveler ses thèmes tandis que son lectorat vieillit.

3 L'ouvrage permet aussi de découvrir derrière le polygraphe polémiste un ardent constructeur, attentif aux petits, dénonçant l'égoïsme des puissants, se consacrant avec bonheur aux colonies de vacances pour les jeunes Parisiens, organisant des ventes de charité avec un vif succès. L'aura de l'écrivain lui permet alors de mobiliser la bourse de ses lecteurs pour le succès de ses projets.

4 Cet excellent ouvrage comporte de plus trois cahiers photographiques. S'il faut un regret, c'est l'arrêt de la bibliographie en 2007. 